time it is highly unlikely to do so and depletion of lymph leads to progressive inanition of the patient. In this case several months elapsed in this manner because the patient was reluctant to undergo operative treatment.

Traditionally surgery for chylothorax means either radical pleurodesis or identification of the site of leakage by lymphography or radioisotope scanning, followed by direct repair, ligation, or lymphoazygos shunting of the lymphatic fistula at thoracotomy. ${ }^{2}$ In this case a high pressure lymphatic system was thought to be present at the level of the diaphragm, which had previously resulted in chyluria and now presented with chylothorax. The aim of treatment was therefore to decompress rather than to seal the fistula. The pleuroperitoneal shunt enables lymph to be shunted to the greater absorptive surface area of the peritoneal cavity and may thus obviate the need for major surgery without compromising the operative field should thoracotomy subsequently prove necessary.
Pleuroperitoneal shunting has been used in the treatment of recalcitrant chylothorax for almost a decade and its successful use has been described in both congenital neonatal chylothorax $^{6}$ and adult cases ${ }^{7}$ of traumatic and malignant aetiology. We believe, however, that this is the first case in which the use of the pleuroperitoneal shunt has been described in chylothorax secondary to filariasis.

1 Lloyd-Davies RW, Edwards JM, Kinmonth JB. Chyluria Br J Urol 1967;39:566-71.

2 Kinmouth JB. Surgery, lymphography and diseases of the chyle and lymph systems. 2nd ed. London: Arnold, 1981.

3 Robinson CLN. The management of chylothorax. Ann Thorac Surg 1985;39:90-5.

4 Manson-Bahr PEC, Bell RD, eds. Manson's tropical diseases. 19th ed. London: Ballière Tindall, 1987.

5 Maegraith B, ed. Adams and Maegraith: Clinical tropical diseases. 9th ed. Oxford: Blackwell, 1989.

6 Azizkhan RG, Canfield J, Alford BA, Rodgers BM Pleuroperitoneal shunts in the management of neonatal chylothorax. J Pediatr Surg 1983;18:842-50.

7 Milsom JW, Kron IL, Rheuban KS. Chylothorax: an assessment of current surgical practice. $J$ Thorac Cardiovasc Surg 1985;89:221-7.

\section{Hypertrophic pulmonary osteoarthropathy in a patient with pulmonary alveolar microlithiasis}

\author{
Salih Emri, Lütfi Cöplü, Z Toros Selçuk, \\ A Altay Sahin, Y Izzettin Baris
}

\begin{abstract}
Hypertrophic pulmonary osteoarthropathy occurred in a patient with proved pulmonary alveolar microlithiasis, an association not previously reported.
\end{abstract}

Pulmonary alveolar microlithiasis is an uncommon disorder of unknown aetiology, characterised by microliths within the alveoli. Diagnosis is usually made from the radiographic appearance. ${ }^{12}$

Finger clubbing has been reported in pulmonary alveolar microlithiasis, ${ }^{134}$ but not hypertrophic pulmonary osteoarthropathy. We report such a patient.

Department of Chest Diseases, Hacettepe University, School of Medicine, Ankara, Turkey

$S$ Emri

Emri

Z T Selplüuk

A A Sahin

Y I Baris

Reprint requests to: Professor Y I Baris

\section{Case report}

Pulmonary alveolar microlithiasis was diagnosed in a 44 year old woman and confirmed by open lung biopsy. Three years later she reported intermittent bilateral pain in the knees and ankles of four months' duration. The pain was associated with swelling at rest and aggravated by walking. She also noted increasing dyspnoea on exertion, and a cough producing yellow sputum. There was no relevant family history. On examination she was obese and had finger clubbing. Her wrists, ankles, metacarpophalangeal joints, and metatarsophalangeal joints were swollen, erythematous, and tender in response to light palpation. Auscultation of the chest disclosed bilateral basal end inspiratory crackles.

The erythrocyte sedimentation rate was $80 \mathrm{~mm}$ in one hour. Rheumatoid factor was present and $C$ reactive protein was increased. Arterial blood gases while she was breathing air were: $\mathrm{pH} 7 \cdot 42$, arterial carbon dioxide tension $\left(\mathrm{PaCO}_{2}\right) 4.2 \mathrm{kPa}$, arterial oxygen tension $\left(\mathrm{PaO}_{2}\right) \quad 9.9 \mathrm{kPa}$. Pulmonary function tests showed mild restriction and a transfer factor (TLCO) of $39 \%$ predicted. A chest radiograph (fig 1) showed very fine, sand like micronodules of calcific density, diffusely affecting both lungs. The appearance was unchanged from a radiograph taken 10 years earlier.

Computed tomography of the chest showed diffuse bilateral calcified densities, predomin-

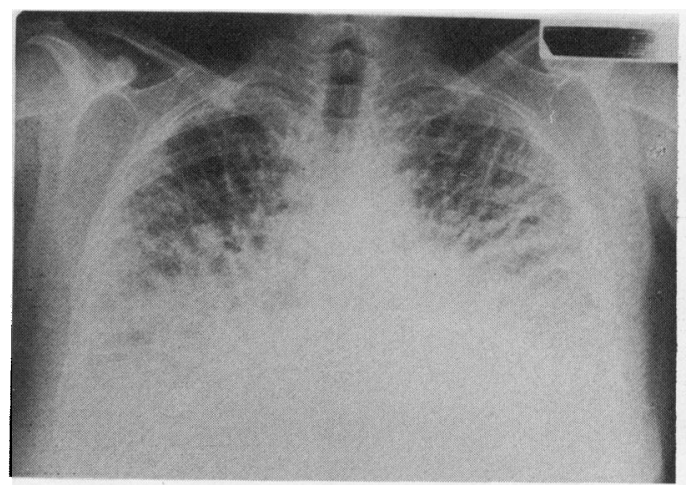

Figure 1 Chest radiograph showing very fine, sand like micronodules of calcific density in both lung fields. 


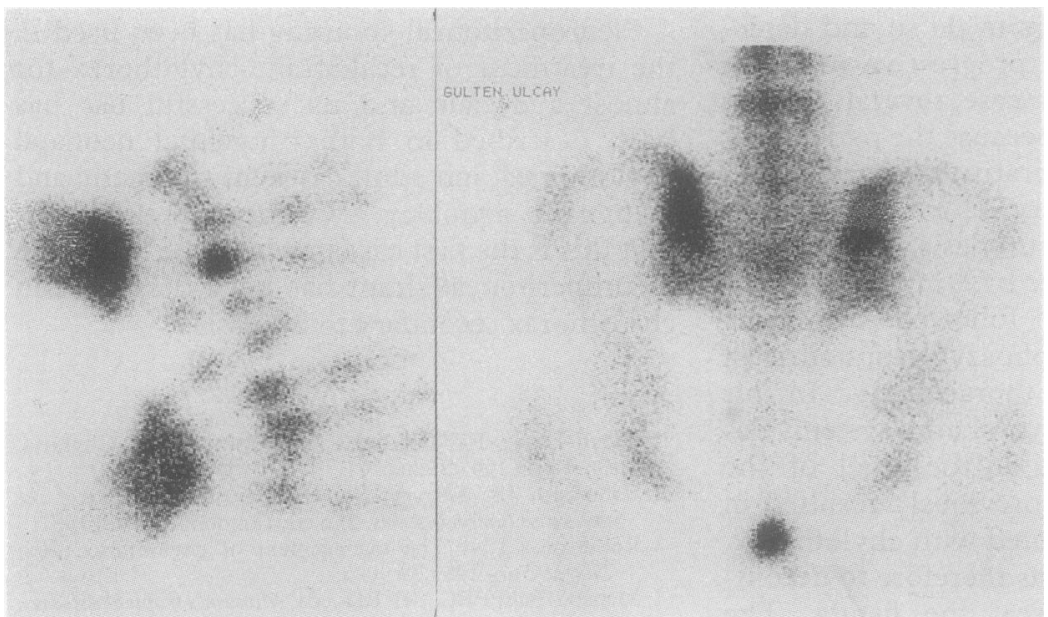

Figure 2 Bone scan showing increased uptake of radioisotope at the diaphysis and metaphysis of the metacarpal bones and both wrists.

antly located at the lung bases, and widespread fibrosis. A radioisotope bone scan showed diffuse and intense uptake through both lungs ${ }^{35}$ and increased uptake at the diaphysis and metaphysis of the metacarpal bones and in both wrists (fig 2). The patient was treated with a non-steroidal anti-inflammatory agent and the pain subsided in the course of a week.

\section{Discussion}

One hundred and sixty nine cases of alveolar microlithiasis have been reviewed. ${ }^{26}$ Clubbing of the fingers has been described in this condition but other features of hypertrophic pulmonary osteoarthropathy have not been reported. ${ }^{7}$ Joint symptoms in hypertrophic pulmonary osteoarthropathy range from mild arthralgia to a restricted range of movement and even ankylosis in advanced cases. ${ }^{8}$ Synovitis, frequently symmetrical, affects metacarpophalangeal joints, wrists, elbows, knees, and ankles. ${ }^{7}$ Complement levels and results of rheumatoid factor and antinuclear antibody tests are usually normal but the erythrocyte sedimentation rate is increased. ${ }^{\text {? }}$ The presence of rheumatoid factor in our patient may be related to its occurrence in fibrosing alveolitis, in which $40 \%$ of patients were found to have it. ${ }^{9}$

Radiographically, detectable periosteal thickening along the shafts of the long and short bones confirms the presence of hypertrophic pulmonary osteroarthropathy. ${ }^{7} 1011$ Radionuclide bone scans are helpful where radiographic features are minimal or absent. Pericortical and periarticular uptake are consistent with synovitis. Isotopic imaging of the hands and feet is a sensitive method of determining the presence and extent of hypertrophic pulmonary osteoarthropathy. ${ }^{12}$ The diaphysis and metaphysis of the metacarpal and metatarsal bones may also be seen to be affected, with increased uptake at the distal phalanges. ${ }^{10}$ The skeletal survey in our case showed subperiosteal bone formation in the distal tibia and the bone scan showed slightly increased uptake in both wrists and metacarpophalangeal joints. This, associated with finger clubbing, confirmed the presence of hypertrophic pulmonary osteoarthropathy in the presence of definitively diagnosed pulmonary alveolar microlithiasis.

1 Sosman MC, Dodd GD, Jones WD, Pillmore GU. The familial occurrence of pulmonary alveolar microlithiasis. AJR 1957;77:947-1012.

2 Cheong W-Y, Wang Y-T, Tan LKA, Poh S-C. Pulmonary alveolar microlithiasis. Australias Radiol 1988;32:401-4.

3 Parakash UB, Barham SS, Rosenow EC III, Brown ML, Payne WS. Pulmonary alveolar microlithiasis. A review including ultrastructural and pulmonary function studies. Mayo Clin Proc 1983;58:290-300.

4 Cale WF, Petsonk EL, Boyd CB. Transbronchial biopsy of Cale WF, Petsonk EL, Boyd CB. Transbronchial biopsy of
pulmonary alveolar microlithiasis. Arch Intern Med 1983;143:358-9.

5 Brown ML, Swee RG, Olson RJ, Bender CE. Pulmonary uptake of $99 \mathrm{~m}$ Tc diphosphonate in alveolar microlithiasis. AJR 1978;131:703-4.

6 Volle E, Kaufmann HJ. Pulmonary alveolar microlithiasis in pediatric patients. A review of the world literature and two new observations. Pediatr Radiol 1987;17:439-42.

7 Altman RD, Tenenbaum J. Hypertrophic osteoarthropathy. In: Kelley WN, Harris EO, Ruddy S, Sledge CB, eds. Textbook of rheumatology. Philadelphia: Saunders, 1985:1594-603.

8 Schechter SL, Bole GG. Hypertrophic osteoarthropathy and rheumatoid arthritis. Simultaneous occurrence in association with diffuse interstitial fibrosis. Arthr Rheum association with

9 Popper MS, Bogdonoff ML, Hughes RL. Interstitial rheumatoid lung disease. Chest 1972;62:243-50.

10 Ali A, Tetalman MR, Fordham EW, et al. Distribution of hypertrophic pulmonary osteoarthropathy. AJR 1980;134:771-80.

11 Galks B, Grossman RF, Day A, Tenenbaum J, Kirsh J, Rebuck AS. Hypertrophic pulmonary osteoarthropathy in four patients with interstitial pulmonary disease. Chest 1985;88:94-7.

12 Rosenthal L, Kirsh J. Observations on radionuclide imaging in hypertrpophic pulmonary osteoarthropathy. Radiology $1976 \cdot 120 \cdot 359-62$. 